\title{
Capsaicin-induced apoptosis in human breast cancer MCF-7 cells through caspase-independent pathway
}

\author{
CHU-CHUNG CHOU ${ }^{1,2 *}$, YAO-CHUNG WU ${ }^{3,4 *}$, YU-FEN WANG ${ }^{5}$, \\ MING-JEN $\mathrm{CHOU}^{2}$, SHOU-JEN KUO ${ }^{3}$ and DAR-REN CHEN $\mathrm{CH}^{3,5}$ \\ ${ }^{1}$ Department of Emergency Medicine, Changhua Christian Hospital, Changhua; ${ }^{2}$ Institute of \\ Medicine, Chung Shan Medical University, Taichung; ${ }^{3}$ Department of Surgery, Changhua \\ Christian Hospital; ${ }^{4}$ Institute of Biology, National Changhua University of Education; \\ ${ }^{5}$ Department of Research, Changhua Christian Hospital, Changhua, Taiwan, R.O.C.
}

Received June 9, 2008; Accepted November 3, 2008

DOI: 10.3892/or_00000269

\begin{abstract}
Capsaicin (trans-8-methyl- $N$-vanillyl-6nonenamide), a significant pungent ingredient in a variety of red peppers of the genus Capsicum, is a type of vanilloid. It has been shown to exert biological activities (anticarcinogenic, antimutagenic and chemopreventive) in many cancer cell lines. It was found that capsaicin induces dose-dependent growth inhibition of MCF-7 cells, which does not express caspase-3. In this study, we investigated the molecular mechanism of capsaicin-induced apoptosis in MCF-7 cells. Treatment with capsaicin for $24 \mathrm{~h}$ resulted in dose-dependent apoptosis in these cells. After the addition of capsaicin, the levels of reactive oxygen species were reduced slightly in the earlier stage of treatment. Interestingly, an elevation of intracellular calcium ion concentration was detected in the MCF-7 cells. In time course and dosage studies, the mitochondrial membrane potential of MCF-7 cells decreased. However, the change was not significant. It is worth noting that the apoptosis-inducing factor translocated into the cytosol and nucleus from the mitochondria. Our results suggest that capsaicin induces cellular apoptosis through a caspase-independent pathway in MCF-7 cells, and that reactive oxygen species and intracellular calcium ion fluctuation has a minimal role in the process.
\end{abstract}

Correspondence to: Professor Dar-Ren Chen, Department of Research, Changhua Christian Hospital, 135 Nanhsiao Street, Changhua 500, Taiwan, R.O.C.

E-mail: darren_chen@cch.org.tw

Dr Shou-Jen Kuo, Department of Research, Changhua Christian Hospital, 135 Nanhsiao Street, Changhua 500, Taiwan, R.O.C.

E-mail: 40225@cch.org.tw

${ }^{*}$ Contributed equally

Key words: capsaicin, breast cancer, caspase-independent, MCF-7, apoptosis-inducing factor

\section{Introduction}

Breast cancer is the most common female cancer worldwide and one of the leading cancer causes of death (1). For patients with advanced breast cancer, adjuvant hormonal therapy, chemotherapy or radiotherapy is applied. The cytotoxic effects of chemotherapeutic drugs are greatest in rapidly proliferating cells as their toxicity to normal tissues occurs mainly at sites which contain a high proportion of such cells, e.g. bone marrow, hair follicles, digestive tract and gonads, and may result in severe and irreversible symptoms. Thus, it is important to find an effective method to kill cancer cells without influencing normal ones.

Apoptosis, one type of programmed cell death (PCD), is the best-defined cell death program counteracting tumor growth. The initiation of apoptosis is largely dependent on cell type and diverse apoptotic stimuli (e.g. oxidative stress, DNA damage, ion fluctuations, cytokines, drugs, growth factor deprivation and irradiation) (2). Clinically, apoptosis contributes to cell death in tumors treated with various anticancer agents. Chemo-, radio- and immunotherapy rely heavily on apoptosis to kill breast cancer cells $(3,4)$.

Depending upon the response to anticancer drugs, two apoptotic pathways have been defined based on a variety of observations: death receptor- (extrinsic) and mitochondriadependent (intrinsic). The extrinsic pathway involves the activation of death receptors, mediated by a death domainformed death-inducing signaling complex, recruitment of procaspase 8 to the death receptor and the successive activation of procaspases 8 and 3 , leading to apoptosis. The intrinsic pathway is mediated by $\mathrm{Bax} / \mathrm{Bak}$ and involves the release of cytochrome c. Bax homo- and heterodimers interact with a voltage-dependent anion channel in the mitochondrial outer membrane to release cytochrome $\mathrm{c}$ by increasing mitochondrial membrane permeability (MMP) via opening of the mitochondrial permeability transition pore $(5)$. When cytochrome $\mathrm{c}$ is released into the cytosol, an apoptosome consisting of Apaf-1 and procaspase 9 is formed, after which dATP activates caspase 9, leading to apoptosis (6). The active caspase 9 leads to activation of one of the effector caspases, 3 or 7 , which cleaves an inhibitor of caspase-activated 
DNAase and produces poly-(ADP-ribose) polymerase (PARP), resulting in $\sim 180$-bp DNA fragmentation.

Mitochondria participate in a caspase-independent pathway, in which an apoptosis-inducing factor (AIF) is required for PARP-1-mediated cell death $(7,8)$. After DNA damage, PARP-1 generates a number of long, branched PARPs. PARP-1 activation initiates a nuclear signal that triggers the release of AIF from mitochondria and then translocates to the nucleus. AIF induces nuclear chromatin condensation and large-scale DNA fragmentation (producing 50-kilobase DNA fragments), and is essential for PCD (9).

It is well known that phytochemicals are considered to have potential value as antioxidants and cancer preventive agents, as well as cancer therapy drugs. Importantly, the majority of these bioactive substances have been reported to exert their anticancer property by blocking cell cycle progression and triggering tumor cell apoptosis. Therefore, cell cycle arrest and the apoptotic induction in tumor cells become significant indicators of the anticancer effect (10). Capsaicin (8-methyl- $N$-vanillyl-6-nonenamide) is a significant pungent ingredient in hot chili of the genus Capsicum. Due to the irritating and pungent property of capsaicin, it is thought to induce tumors. In reports regarding the effects of capsaicin on carcinogenesis from animal studies, it was shown that capsaicin itself was mutagenic (11) and promoted tumor formation (12). Evidence indicates that chili pepper consumption may increase cancer risk in humans $(13,14)$. However, other investigators showed that capsaicin had anticarcinogenic and anti-mutagenic activities by demonstrating the in vitro effect of capsaicin on inhibiting the growth of immortalized or malignant cells through apoptotic induction (15-17). In normal cells, however, capsaicin is largely ineffective. (18) Tuoya et al demonstrated that capsaicin induced apoptosis in human breast cancer MCF-7 cells (18) via a caspase-dependent pathway not involving caspase-3. Nevertheless, there is no study on the relationship between the caspase-independent pathway and capsaicin-induced apoptosis in human breast cancer cells at present.

MCF-7 cells do not express caspase- 3 due to the functional 47-bp deletion inside the exon 3 of the CASP-3 gene, although they remain responsive to many apoptotic stimuli (19). Caspase 3-mediated events appeared to be dispensable in determining the overall killing of cells, since 50-kb DNA fragments, chromatin condensation, Rb, gelsolin and PARP cleavage also occurred in caspase-3-deficient MCF-7 cells (20-22). When caspase-3 has no contribution to cell death, cells can still die apoptotically by non-caspase-3-dependent or caspase-independent mechanisms due to the activation of other effective caspases or the nuclear translocation of AIF. This study aimed to investigate the molecular mechanism of capsaicin-induced apoptosis in caspase 3-deficient MCF-7 cells, and specifically, whether the caspase-independent pathway is involved.

\section{Materials and methods}

Cell line. The human breast cancer cell line MCF-7 was obtained from the Food Industry Research and Development Institute (Hsinchu, Taiwan). Cells were grown at $37^{\circ} \mathrm{C}$ under humidified $5 \% \mathrm{CO}_{2}$ and $95 \%$ air at one atmosphere in minimum essential medium supplemented with $10 \%$ fetal bovine serum (FBS), $10 \mathrm{ng} / \mathrm{ml}$ penicillin-streptomycin and $1 \%$ L-glutamine. The cell culture-related reagents were purchased from Gibco BRL (Grand Island, NY, USA).

Determinations of cellular morphological changes and cell viability. MCF-7 cells $\left(\sim 3 \times 10^{5} /\right.$ well $)$ were plated in 12-well plates and grown for $24 \mathrm{~h}$. Various concentrations of capsaicin (Sigma, St. Louis, MO, USA) were added, while in the control only DMSO (solvent) was added. After various time periods of treatment, a phase contrast microscope was used to determine the morphological changes (23). To determine cell viability, the trypan blue-dye exclusion protocol was applied. Briefly, cell suspension in phosphate-buffered saline (PBS) ( $\mathrm{pH} 7.4$ ) was mixed with $0.4 \%$ trypan blue (Gibco BRL) at the ratio of $1: 4$, and the numbers of stained (dead) and unstained cells (live) were counted using a hemocytometer under a light microscope (BX61, Olympus, Tokyo, Japan).

Effect of capsaicin on cell cycle progression and apoptosis of MCF-7 cells as determined by flow cytometry. To estimate the proportion of MCF-7 cells in different phases of the cell cycle affected by capsaicin, cellular DNA contents were measured by flow cytometry. MCF-7 cells ( $\sim 5 \times 10^{5} /$ well) were plated in 12-well plates, and incubated with different concentrations of capsaicin. For the time course study, cells were incubated with $50 \mu \mathrm{M}$ capsaicin for different time periods. The cells were then harvested by centrifugation, fixed with $70 \%$ ethanol (in PBS) on ice overnight, and resuspended in PBS containing $4 \mu \mathrm{g} / \mathrm{ml}$ of propidium iodide (PI) (Sigma), $0.1 \mathrm{mg} / \mathrm{ml}$ RNase A and $0.1 \%$ Triton X-100 in the dark. The cell suspension was incubated at $37^{\circ} \mathrm{C}$ for $30 \mathrm{~min}$. The cell cycle was determined and analyzed with flow cytometry (Becton-Dickinson, San Jose, CA, USA) equipped with an argonion laser at a $488 \mathrm{~nm}$ wavelength.

Determination of DNA damage induced by capsaicin in MCF-7 cells by alkaline single-cell gel electrophoresis (Comet assay). To examine the levels of oxidized pyrimidines and purines of DNA in treated cells, MCF-7 cells were harvested for the Comet assay after various concentrations of capsaicin treatment for $24 \mathrm{~h}$. The slides were washed twice with an enzyme buffer (40 mM HEPES, 0.1 M KCl, $0.5 \mathrm{mM}$ EDTA and $0.2 \mathrm{mg} / \mathrm{ml} \mathrm{BSA}, \mathrm{pH} 8.0$ ). The slides were then placed in a double row in a $260-\mathrm{mm}$ wide horizontal electrophoresis tank containing $0.3 \mathrm{M}$ of $\mathrm{NaOH}$ and $1 \mathrm{mM}$ of $\mathrm{Na}_{2}$ EDTA (pH 13.0) for $10 \mathrm{~min}$. Electrophoresis $(30 \mathrm{~V}, 300 \mathrm{~mA})$ was conducted for $15 \mathrm{~min}$ at $4^{\circ} \mathrm{C}$. Following electrophoresis, the slides were soaked in a cold neutralizing buffer $(400 \mathrm{mM}$ Tris- $\mathrm{HCl}$ buffer, $\mathrm{pH} \mathrm{7.5)}$ at $4^{\circ} \mathrm{C}$ for $10 \mathrm{~min}$. The slides were dried in methanol for 5 min and stored in a low humidity environment before staining with $40 \mu 1$ of PI $(2.5 \mu \mathrm{g} / \mathrm{ml})$.

Flow cytometry detection of ROS in capsaicin-treated MCF-7 cells. Intracellular oxidative stress was assayed by measuring the concentration of intracellular hydrogen peroxide formed by serial enzymatic reactions of 2',7'-dichlorodihydrofluorescein diacetate (DCFH-DA) (24). MCF-7 cells ( 2x105/well) in 12 -well plates were treated with $150 \mu \mathrm{M}$ capsaicin, harvested and washed twice, re-suspended in $500 \mu 1$ of DCFH-DA 
(Calbiochem, La Jolla, CA) (final concentration, $10 \mu \mathrm{M}$ ), incubated at $37^{\circ} \mathrm{C}$ for $30 \mathrm{~min}$ and analyzed by flow cytometry.

Flow cytometry of intracellular $\mathrm{Ca}^{2+}$ in capsaicin-treated MCF-7 cells. The intracellular $\mathrm{Ca}^{2+}$ levels of the MCF-7 cells were assayed by using 1-[2-amino-5-(6-carboxyindol-2-yl) phenoxy]-2-(2'-amino-5'-methylphenoxy) ethane-N,N,N',N'tetraacetic acid pentaacetoxymethyl ester (Indo 1/AM) (Calbiochem). MCF-7 cells ( 2x105/well) in 12-well plates were treated with $150 \mu \mathrm{M}$ capsaicin. The cells were harvested and washed twice, once for apoptosis and then for resuspension in Indo 1/AM ( $3 \mu \mathrm{g} / \mathrm{ml})$. The cells were incubated at $37^{\circ} \mathrm{C}$ for $30 \mathrm{~min}$ and analyzed by flow cytometry.

Flow cytometry detection of MMP in capsaicin-treated MCF-7 cells. To detect the changes of MMP induced by capsaicin treatment, MCF-7 cells $\left(\sim 2 \times 10^{5} /\right.$ well $)$ in a 12-well plate were treated with various concentrations of capsaicin for $24 \mathrm{~h}$, or incubated with $150 \mu \mathrm{M}$ capsaicin for various time periods. The cells were harvested and washed twice, resuspended in $500 \mu 1$ of 3,3'-dihexyloxacarbocyanine iodide $\left(\mathrm{DiOC}_{6}\right)\left(\right.$ Calbiochem) $(4 \mathrm{~mol} / \mathrm{l})$, incubated at $37^{\circ} \mathrm{C}$ for $30 \mathrm{~min}$ and analyzed by flow cytometry.

Western blotting for examining the effect of capsaicin on P53, Bax and Bcl-2 in MCF-7 cells. Total cellular proteins were extracted from MCF-7 cells treated with or without various concentrations of capsaicin for $48 \mathrm{~h}$. Then, P53, Bax and $\mathrm{Bcl}-2$ protein expression was examined by sodium dodecyl sulfate polyacrylamide gel electrophoresis (SDSPAGE) and Western blots. In these analyses, the protein concentration was standardized among the samples. Aliquots of cell lysates containing $\sim 50 \mu \mathrm{g}$ of total cellular proteins were separated on $10 \%$ SDS-PAGE, and electrophoresed at $20 \mathrm{volt} / \mathrm{cm}$ for $120 \mathrm{~min}$. The proteins in the SDS-PAGE were transferred onto the nitrocellulose membrane. After washing the blotted membrane twice with water, the membrane was blocked in freshly prepared phosphate-buffered solution containing 5\% non-fat dry milk and Tween-20 for $30 \mathrm{~min}$ at room temperature with constant shaking, and incubated overnight at $4^{\circ} \mathrm{C}$ with the desired primary antibody. The membrane was then washed twice with water and incubated with the secondary antibody, goat anti-mouse IgG linked to horseradish peroxidase (1:3,000 dilution) for $90 \mathrm{~min}$ at room temperature with gentle shaking. The immunoreactive protein bands were visualized using an enhanced chemiluminescence kit (Upstate, Lake Placid, NY, USA) according to the manufacturer's instructions.

DNA fragmentation. To determine the occurrence of DNA fragmentation, total DNA was extracted from control and treated cells using the Gentra DNA isolation kit according to the manufacturer's instructions. In brief, the attached and detached cells floating in the medium were collected by scraping and centrifuging (2,000 $\mathrm{g}$ for $10 \mathrm{~min})$. After incubating with $300 \mu \mathrm{l}$ lysis buffer at $65^{\circ} \mathrm{C}$ for $30 \mathrm{~min}$, the lysates were digested by $1.5 \mu 1 \mathrm{RNase} \mathrm{A}(4 \mathrm{mg} / \mathrm{ml})$ at $37^{\circ} \mathrm{C}$ for $1 \mathrm{~h}$. The proteins were excluded by adding $100 \mu \mathrm{l}$ protein precipitation solution and cleared with a microfuge. DNA in the supernatants was precipitated by incubating with $300 \mu 1$ isopropyl ethanol at $-20^{\circ} \mathrm{C}$ for $1 \mathrm{~h}$. The DNA pellets were separated, air-dried and dissolved in TE buffer ( $\mathrm{pH} 7.4)$. Equal amounts of DNA were resolved with $1.5 \%$ agarose gel and stained with $0.5 \mu \mathrm{g} / \mathrm{ml}$ ethidium bromide.

Immunofluorescence staining and confocal microscopy. Cells for confocal immunofluorescence analysis were grown on commercial silane-coated glass slides for $24 \mathrm{~h}$ before they were fixed. The cells were treated with various concentrations of capsaicin for $24 \mathrm{~h}$. The medium was removed, and the cells were fixed with pre-cooled acetone-methanol $(1: 1)$ at $-20^{\circ} \mathrm{C}$. After drying, the cells were stored at $-20^{\circ} \mathrm{C}$ before immunofluorescence staining was performed. The samples were blocked with $1 \%$ bovine serum albumin in PBS for $60 \mathrm{~min}$ before incubation with monoclonal antibodies against AIF (kindly offered by Professor Kuan-Chih Chow) for a further $60 \mathrm{~min}$. The cells were then incubated with a fluorescein isothiocyanate-labeled rabbit anti-mouse secondary antibody for $60 \mathrm{~min}$. The nucleus was labeled using 4',6-diamidino2-phenylindole dihydrochloride (Sigma) according to the manufacturer's instructions. Confocal microscopy was performed on a Zeiss laser scanning confocal microscope (LSM510, Zeiss, Chicago, IL, USA) with a 63x water objective. To avoid cross talk between the different fluorochromes, images were acquired in a $0.9-\mu \mathrm{M}$ sequential manner.

Statistical analysis. Student's t-test was used for statistical analysis of the capsaicin-treated and control groups.

\section{Results}

Effects of capsaicin on morphological changes and cell viability of human breast cancer MCF-7 cells. After MCF-7 cells were treated with or without various concentrations of capsaicin for $24 \mathrm{~h}$, cell morphology was observed under a phase contrast microscope. Capsaicin-treated cells lost their normal shape, suggesting that they were dying (Fig. 1a). In the trypan blue exclusion assay, capsaicin treatment for the various time periods decreased the percentage of viable cells from the capsaicin-treated group compared to the control group. These effects were dose-dependent (Fig. 1b).

Induction of apoptosis by capsaicin on MCF-7 cells was examined by flow cytometry. We studied the occurrence of apoptosis of MCF-7 cells with treatment by various concentrations of capsaicin. The results from flow cytometric assays showed that the cell number of the sub-G1 phase rose with the increased capsaicin concentrations, and confirmed that capsaicin induced apoptosis in MCF-7 cells (Fig. 2).

Induction of DNA damage on MCF-7 cells by capsaicin. To verify whether DNA damage occurred in the apoptosis of MCF-7 cells induced by capsaicin, Comet assay was used. The results indicated that DNA damage existed in capsaicintreated MCF-7 cells based on the dose of capsaicin treatment, and that these effects were dose-dependent (Fig. 3).

ROS production in MCF-7 cells after treatment with various concentrations of capsaicin, using flow cytometry. After 
a.

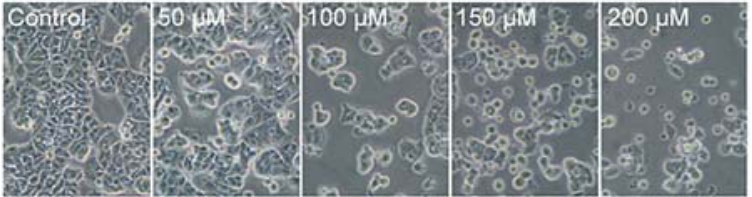

b.

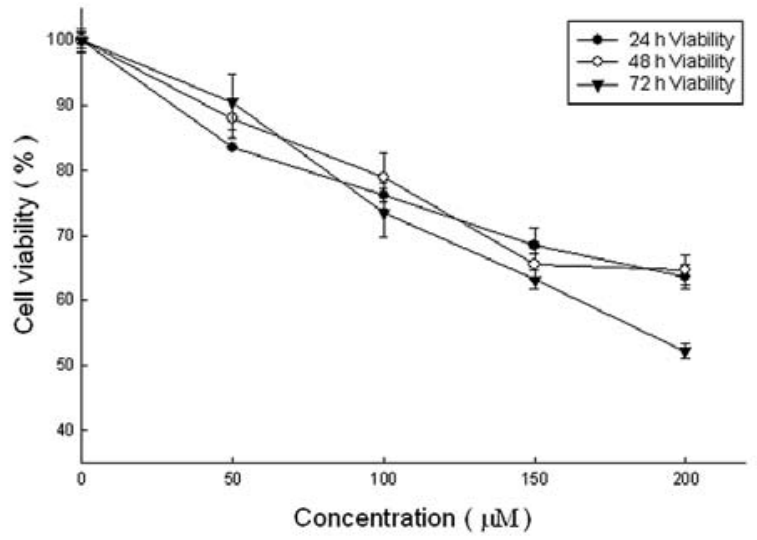

Figure 1. (a) Morphological changes of human breast cancer MCF-7 cells in response to capsaicin. MCF-7 cells were treated with varying concentrations of capsaicin for $24 \mathrm{~h}$, examined under a phase contrast microscope and photographed. (b) MCF-7 cell viability after capsaicin treatment. MCF-7 cells were treated with different concentrations of capsaicin for $24 \mathrm{~h}$, and the viable cells were determined by the trypan blue-dye exclusion method. Each point is the mean $\pm \mathrm{SD}$ of three experiments.

MCF-7 cells were treated with or without capsaicin for various time periods, ROS production was analyzed and quantitated by flow cytometry. The results indicated that the percentage of ROS was not significantly different between the capsaicin-treated and control groups (Fig. 4a). Capsaicin did not affect ROS production (in the groups examined, the dose and time treatment remained unclear).

Effects of capsaicin on the production of $\mathrm{Ca}^{2+}$ from $\mathrm{MCF}-7$ cells. Changes of intracellular $\mathrm{Ca}^{2+}$ levels related to capsaicin treatment were analyzed by flow cytometry. After MCF-7 cells a.
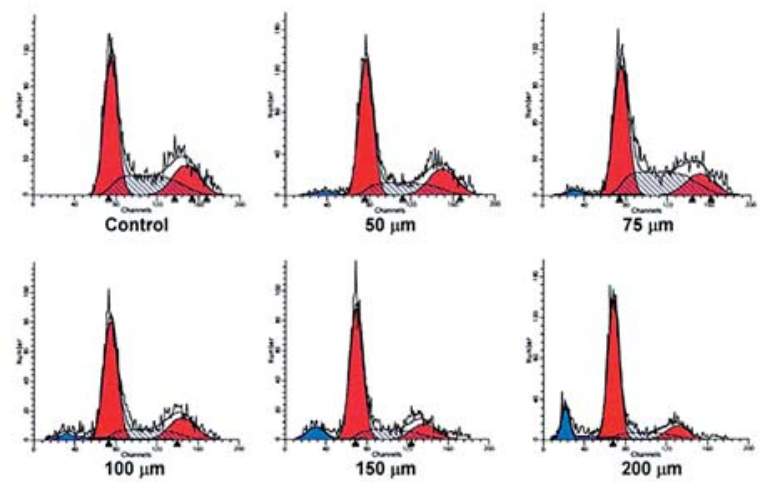

b.

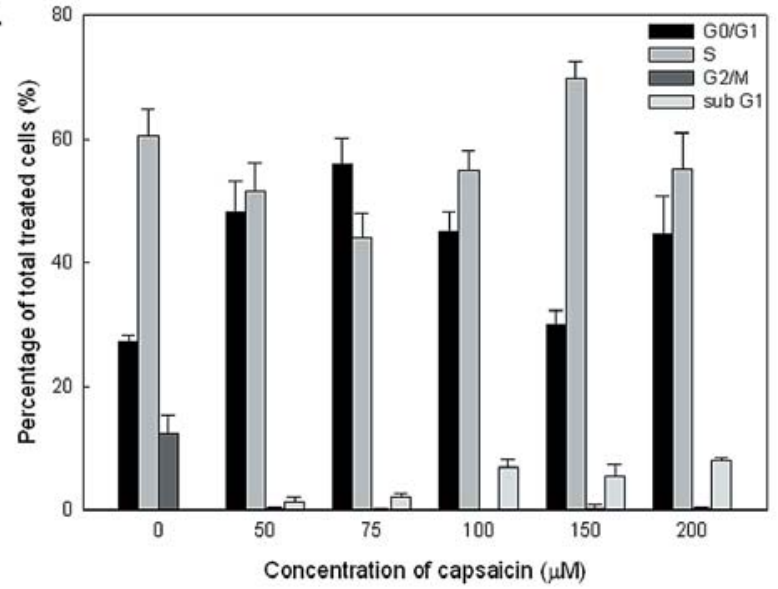

Figure 2. PI staining analysis of the effects of capsaicin on apoptosis in human breast cancer MCF-7 cells. (a) The MCF-7 cells were incubated with various concentrations of capsaicin for $48 \mathrm{~h}$, and cell cycle and apoptosis were determined by flow cytometry. (b) Statistical analysis of data from (a). Data represent the mean $\pm \mathrm{SD}$ of three experiments.

were treated with $150 \mu \mathrm{M}$ capsaicin for up to $2 \mathrm{~h}$, the intracellular $\mathrm{Ca}^{2+}$ level increased, and then returned to the initial level after up to $11 \mathrm{~h}$ of capsaicin treatment (Fig. 4b), implying that intracellular $\mathrm{Ca}^{2+}$ is not involved in capsaicin-induced apoptosis.
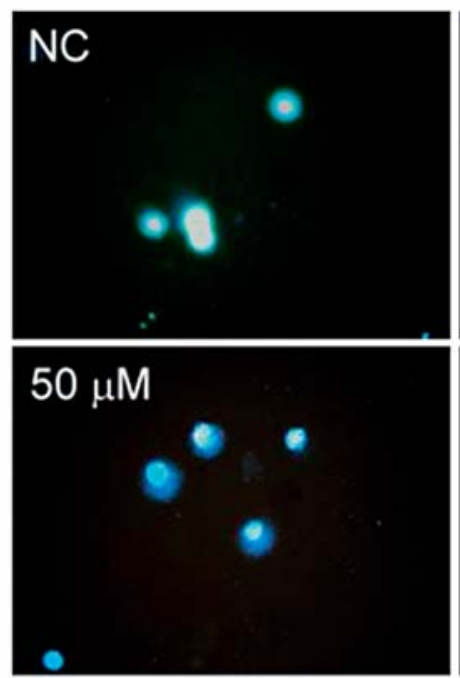

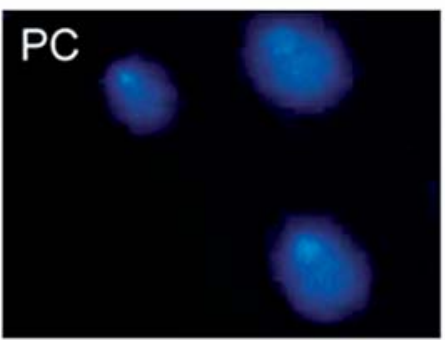

$75 \mu \mathrm{M}$
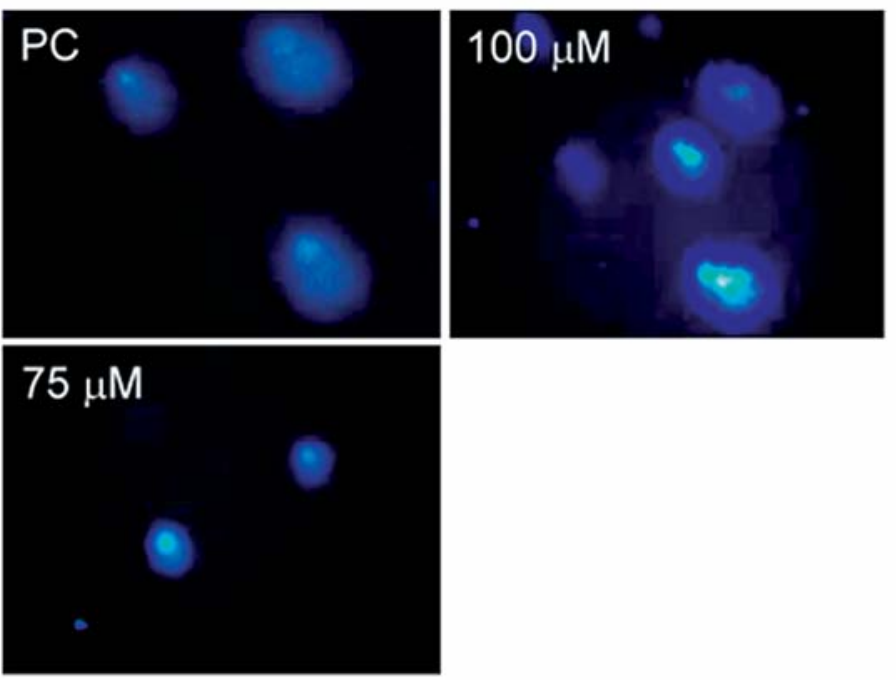

Figure 3. DNA damage determination for capsaicin-treated MCF-7 cells. MCF-7 cells were incubated with capsaicin for 24 h and DNA damage was analyzed by Comet assay. $\mathrm{NC}$, untreated negative and $\mathrm{PC}$, positive controls $\left(\mathrm{H}_{2} \mathrm{O}_{2}\right.$-treated). 
a.

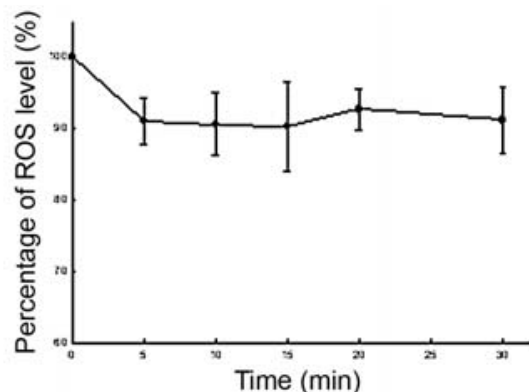

c.



b.

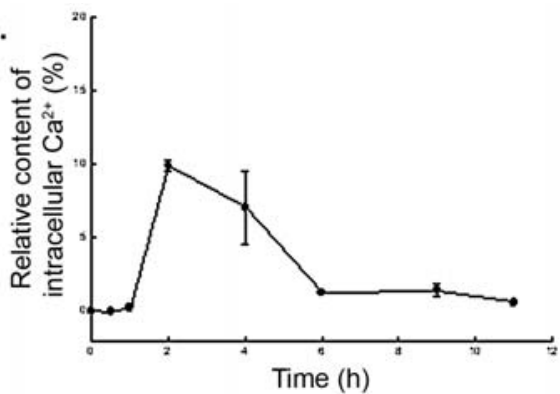

d.

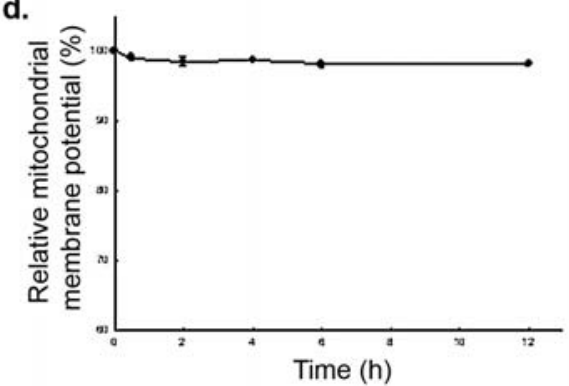

Figure 4. (a) ROS changes in capsaicin-treated human breast cancer MCF-7 cells with $150 \mu \mathrm{M}$ capsaicin for the various time periods. The percentage of DCFH-DA-stained cells were determined by flow cytometry. (b) Changes of intracellular $\mathrm{Ca}^{2+}$ concentration in MCF-7 cells with $150 \mu \mathrm{M}$ capsaicin for various time periods. The percentage of Indo-1/AM-stained cells was determined by flow cytometry. (c) A dose-dependent analysis of MMP changes of 24-h capsaicintreated MCF-7 cells by flow cytometry. (d) A time course-dependent analysis of MMP changes of 24-h capsaicin-treated MCF-7 cells by flow cytometry. The data represent the mean $\pm \mathrm{SD}$ of three experiments.

a.

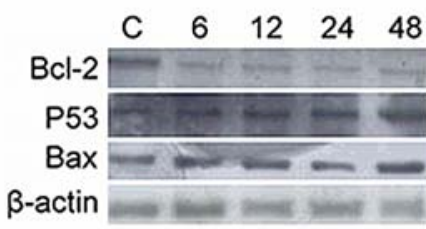

C.
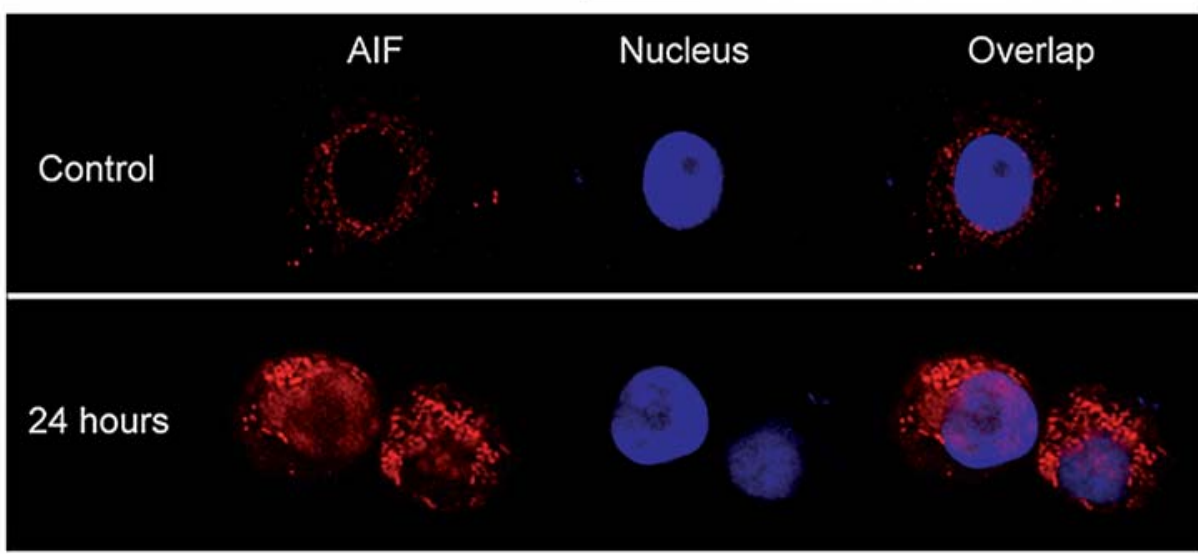

Figure 5. Apoptosis-related changes in MCF-7 cells after capsaicin treatment. (a) Representative results of Western blotting showed changes in the levels of Bcl-2, P53 and Bax in MCF-7 cells after treatment with capsaicin. (b) DNA fragmentation assay of MCF-7 cells after capsaicin treatment for $24 \mathrm{~h}$. Lane M is a 100-bp DNA marker and lane $\mathrm{C}$ is an untreated control. (c) AIF translocated into the nuclei of capsaicin-treated MCF-7 cells. MCF-7 cells were treated with $150 \mu \mathrm{M}$ for $24 \mathrm{~h}$, and then prepared for confocal immunofluorescence staining. The upper and lower parts are untreated control and capsaicin-treated, respectively. Left panel (red), AIF distribution; middle panel (blue), a DAPI-stained nucleus and right panel, the merged image of AIF and the nucleus. 
Effects of capsaicin on the levels of mitochondrial membrane potential from MCF-7 cells. After MCF-7 cells were treated with or without various concentrations of capsaicin for various time periods, the mitochondrial membrane potential levels were analyzed and quantified by flow cytometry. The results showed that changes of the mitochondrial membrane potential were not significantly lower in the capsaicin-treated than in the control group. Increasing the dose of capsaicin led to a slight decrease in the mitochondrial membrane potential in the examined MCF-7 cells (Fig. 4c). After various time periods of $150 \mu \mathrm{M}$ capsaicin treatment, the mitochondrial membrane potential in MCF-7 cells was also affected (Fig. 4d).

Capsaicin affected P53, Bcl-2 and Bax expression in MCF-7 cells. Western blotting experiments indicated that capsaicin increased the expression of P53 and Bax, and decreased that of Bcl-2, which may have led to apoptosis in these examined cells (Fig. 5a).

No low molecular weight DNA fragmentation occurred in capsaicin-treated MCF-7 cells. Following MCF-7 cell treatment with various concentrations of capsaicin $24 \mathrm{~h}$, no low molecular weight DNA fragmentation was observed in the $1.5 \%$ agarose gel electrophoresis (Fig. 5b). This result may be related to the caspase-3 deficiency of MCF-7 cells.

AIF translocated into the nuclei of capsaicin-treated MCF-7 cells. To elucidate whether the caspase-independent pathway was involved in the capsaicin-induced apoptosis of caspase 3deficient MCF-7 cells, the distribution of AIFs was detected by using immunofluorescence staining. Without capsaicin treatment, AIFs resided in the mitochondria around the nucleus (Fig. 5c, upper part). They were released from the mitochondria and translocated into the nuclei of MCF-7 cells after $24 \mathrm{~h}$ of exposure to capsaicin (Fig. 5c, lower part), suggesting that the caspase-independent pathway was switched on, followed by apoptosis.

\section{Discussion}

Natural polyphenols have been documented to have beneficial effects on health, and these compounds have drawn public attention due to their antioxidant activity. In this study, we found that in addition to the antioxidation activity, capsaicin induced apoptosis via the mitochondrial pathway without ROS production in MCF-7 cells. In contrast, capsaicin treatment led to a decrease in the ROS level of MCF-7 cells. These results were inconsistent with what has been observed in H-ras-transformed MCF10A cells, in which the generation of ROS was believed to be essential for the inhibitory effect of capsaicin on cell growth, possibly by suppressing Rac 1 activity $(18,25,26)$.

Capsaicin toxicity is minimal at low doses. However, it has been suggested that capsaicin is converted into a mutagenic or carcinogenic form through metabolism. A few metabolic mechanisms of capsaicin have been explored to explain its toxicity, such as the production of an electrophilic epoxide, a phenoxy radical, or O-demethylation and oxidation to produce semiquinone and quinone derivatives (27). It was shown that liver cytochrome P450 E21 (CYPE21) was responsible for converting capsaicin into a phenoxy radical that either dimerizes or covalently binds to CYPE21, inactivating the enzyme (27). The phenoxy radical is involved in mutagenesis by capsaicin. Degradation of capsaicin to electrophilic intermediates that covalently react with DNA, RNA or proteins, is believed to be related to capsaicin-induced mutagenicity and carcinogenicity (28).

However, capsaicin shows some protective effects from chemical toxins, including chemical carcinogens. Dimethylnitrosamine (DMN), a known animal carcinogen, is usually a potent mutagen in the Ames assay. When conducting an Ames assay, upon exposure to DMN and capsaicin, the mutagenicity of the DMN was effectively destroyed, suggesting that capsaicin binds to a cytochrome P450 enzyme, one believed to activate potentially cancer-causing polycyclic aromatic hydrocarbons (PAHs) $(27,29)$. The implication is that capsaicin interrupts nitrosamine or PAH metabolism, and prevents their harmful transformation into potent mutagens. Therefore, this common and peppery food ingredient may have the dubious distinction of presenting a low-level cancer risk to the gut while simultaneously neutralizing enzymes that may otherwise attack classes of other carcinogens, which explains the reason for capsaicin protecting cells from chemical carcinogen impairment.

Successful treatment with chemotherapeutic drugs is largely dependent on their ability to trigger cell death in tumor cells, and the activation of apoptosis is at least partially involved in the caspase-independent pathway (30). Most cytotoxic agents trigger the mitochondrial pathway, but the death receptors have also been reported to be involved in chemotherapy-induced apoptosis $(31,32)$. However, evidence suggests that there are forms of chemotherapy-induced cell death that cannot readily be classified as apoptosis or necrosis, but correlate more with the apoptosis-/necrosis-like PCD model (33-35). In general, MCF-7 cells exhibit a reduced sensitivity to a variety of anti-cancer drugs. The resistance results, in part, from a deficiency of caspase-3 activity, which is the significant executioner caspase.

AIF is a phylogenetically-conserved mitochondrial intermembrane flavoprotein that has the ability to induce apoptosis in a caspase-independent manner. Previous reports indicated that injection of the anti-AIF antibodies or knockout of the AIF gene may alleviate the progression of apoptosis, suggesting that AIF is required for cell death after certain cell stresses (36). Staurosporine induces mitochondrial dysfunction and AIF translocation into the nucleus after the activation of nuclear apoptosis in non-small cell lung carcinoma cells resistant to radio- or chemotherapy (37). These results suggest that the caspase-dependent pathway is less effective, although caspase-dependent and -independent pathways coexist. Furthermore, resistant cells may be more susceptible to AIFmediated caspase-independent cell death. In this study, AIF was shown to translocate from mitochondria to the nuclei after capsaicin treatment, implying that apoptosis of MCF-7 cells was via the caspase-independent pathway.

In summary, our study showed that capsaicin induced cell death in caspase-3-deficient MCF-7 cells via caspaseindependent apoptosis. This is the first study to reveal the possible pathway of capsaicin-induced cell death. Our data provide a new insight into anti-tumor chemoprevention 
schemes, although the mechanisms of capsaicin-induced cell death in caspase-3-deficient breast cancer cells need to be further clarified.

\section{Acknowledgments}

This work was supported by the Changhua Christian Hospital.

\section{References}

1. World Health Organization: WHO Fact sheet No. 297: Cancer. World Health Organization. http://www.who.int/mediacentre/ factsheets/fs297/en/index.html, 2006.

2. Green D and Kroemer G: The central executioners of apoptosis: caspases or mitochondria? Trends Cell Biol 8: 267-271, 1998.

3. Debatin K: Activation of apoptosis pathways by anticancer treatment. Toxicol Lett 112-113: 41-48, 2000

4. Shao ZM, Li J, Wu J, et al: Neo-adjuvant chemotherapy for operable breast cancer induces apoptosis. Breast Cancer Res Treat 53: 263-269, 1999.

5. Verrier F, Deniaud A, Lebras M, et al: Dynamic evolution of the adenine nucleotide translocase interactome during chemotherapy-induced apoptosis. Oncogene 23: 8049-8064, 2004.

6. Cain K, Bratton SB and Cohen GM: The Apaf-1 apoptosome: a large caspase-activating complex. Biochimie 84: 203-214, 2002.

7. Hong SJ, Dawson TM and Dawson VL: Nuclear and mitochondrial conversations in cell death: PARP-1 and AIF signaling. Trends Pharmacol Sci 25: 259-264, 2004.

8. Yu SW, Wang H, Poitras MF, et al: Mediation of poly (ADPribose) polymerase-1-dependent cell death by apoptosis-inducing factor. Science 297: 259-263, 2002.

9. Lakhani SA, Masud A, Kuida K, et al: Caspases 3 and 7: key mediators of mitochondrial events of apoptosis. Science 311 : 847-851, 2006.

10. Smets LA: Programmed cell death (apoptosis) and response to anti-cancer drugs. Anticancer Drugs 5: 3-9, 1994.

11. Azizan A and Blevins RD: Mutagenicity and antimutagenicity testing of six chemicals associated with the pungent properties of specific spices as revealed by the Ames Salmonella/microsomal assay. Arch Environ Contam Toxicol 28: 248-258, 1995

12. Agrawal RC, Wiessler M, Hecker E and Bhide SV: Tumourpromoting effect of chilli extract in BALB/c mice. Int J Cancer 38: 689-695, 1986

13. Lee JK, Park BJ, Yoo KY and Ahn YO: Dietary factors and stomach cancer: a case-control study in Korea. Int J Epidemiol 24: 33-41, 1995

14. Lopez-Carrillo L, Hernandez Avila M and Dubrow R: Chili pepper consumption and gastric cancer in Mexico: a casecontrol study. Am J Epidemiol 139: 263-271, 1994.

15. Morre DJ, Chueh PJ and Morre DM: Capsaicin inhibits preferentially the NADH oxidase and growth of transformed cells in culture. Proc Natl Acad Sci USA 92: 1831-1835, 1995.

16. Takahata K, Chen X, Monobe $K$ and Tada M: Growth inhibition of capsaicin on HeLa cells is not mediated by intracellular calcium mobilization. Life Sci 64: PL165-PL171, 1999.

17. Roy M, Chakraborty S, Siddiqi M and Bhattacharya RK: Induction of apoptosis in tumor cells by natural phenolic compounds. Asian Pac J Cancer Prev 3: 61-67, 2002.

18. Tuoya, Baba N, Shimoishi Y, et al: Apoptosis induction by dohevanil, a DHA substitutive analog of capsaicin, in $\mathrm{MCF}-7$ cells. Life Sci 78: 1515-1519, 2006.
19. Janicke RU, Sprengart ML, Wati MR and Porter AG: Caspase-3 is required for DNA fragmentation and morphological changes associated with apoptosis. J Biol Chem 273: 9357-9360, 1998.

20. Janicke RU, Ng P, Sprengart ML and Porter AG: Caspase-3 is required for alpha-fodrin cleavage but dispensable for cleavage of other death substrates in apoptosis. J Biol Chem 273: $15540-15545,1998$.

21. Mathiasen IS, Lademann U and Jaattela M: Apoptosis induced by vitamin $\mathrm{D}$ compounds in breast cancer cells is inhibited by Bcl-2 but does not involve known caspases or p53. Cancer Res 59: 4848-4856, 1999.

22. Xue LY, Chiu SM and Oleinick NL: Photodynamic therapyinduced death of MCF-7 human breast cancer cells: a role for caspase- 3 in the late steps of apoptosis but not for the critical lethal event. Exp Cell Res 263: 145-155, 2001.

23. Lin CC, Kao ST, Chen GW, Ho HC and Chung JG: Apoptosis of human leukemia HL-60 cells and murine leukemia WEHI-3 cells induced by berberine through the activation of caspase- 3 . Anticancer Res 26: 227-242, 2006.

24. Jakubowski W and Bartosz G: 2,7-dichlorofluorescin oxidation and reactive oxygen species: what does it measure? Cell Biol Int 24: 757-760, 2000 .

25. Hwang JT, Park IJ, Shin JI, et al: Genistein, EGCG, and capsaicin inhibit adipocyte differentiation process via activating AMPactivated protein kinase. Biochem Biophys Res Commun 338: 694-699, 2005.

26. Kim S and Moon A: Capsaicin-induced apoptosis of H-rastransformed human breast epithelial cells is Rac-dependent via ROS generation. Arch Pharm Res 27: 845-849, 2004.

27. Surh YJ and Lee SS: Capsaicin, a double-edged sword: toxicity, metabolism, and chemopreventive potential. Life Sci 56: 1845-1855, 1995

28. Olajos EJ and Salem H: Riot control agents: pharmacology, toxicology, biochemistry and chemistry. J Appl Toxicol 21: 355-391, 2001.

29. Surh YJ, Lee RC, Park KK, Mayne ST, Liem A and Miller JA: Chemoprotective effects of capsaicin and diallyl sulfide against mutagenesis or tumorigenesis by vinyl carbamate and $\mathrm{N}$ nitrosodimethylamine. Carcinogenesis 16: 2467-2471, 1995.

30. Fisher DE: Apoptosis in cancer therapy: crossing the threshold. Cell 78: 539-542, 1994.

31. Friesen C, Fulda S and Debatin KM: Cytotoxic drugs and the CD95 pathway. Leukemia 13: 1854-1858, 1999.

32. Green DR: Apoptotic pathways: paper wraps stone blunts scissors. Cell 102: 1-4, 2000.

33. Leist $\mathbf{M}$ and Jaattela $\mathbf{M}$ : Four deaths and a funeral: from caspases to alternative mechanisms. Nat Rev Mol Cell Biol 2: 589-598, 2001.

34. Brown JM and Wouters BG: Apoptosis: mediator or mode of cell killing by anticancer agents? Drug Resist Updat 4: 135-136, 2001.

35. Schmitt CA and Lowe SW: Apoptosis is critical for drug response in vivo. Drug Resist Updat 4: 132-134, 2001.

36. Cande C, Cohen I, Daugas E, et al: Apoptosis-inducing factor (AIF): a novel caspase-independent death effector released from mitochondria. Biochimie 84: 215-222, 2002.

37. Joseph B, Marchetti P, Formstecher P, Kroemer G, Lewensohn R and Zhivotovsky B: Mitochondrial dysfunction is an essential step for killing of non-small cell lung carcinomas resistant to conventional treatment. Oncogene 21: 65-77, 2002. 